\title{
INVENTÁRIO QUALI-QUANTITATIVO DA ARBORIZAÇÃO VIÁRIA DE UM TRECHO DA RODOVIA PA-275 NO MUNICÍPIO DE PARAUAPEBAS-PA
}

\author{
QUALI- QUANTITATIVE INVENTORY OF URBAN FORESTRY OF A STRETCH OF \\ PA 275 HIGHWAY IN THE MUNICIPALITY OF PARAUAPEBAS - PA
}

\author{
Carielle Cristina da Silva Ferro ${ }^{1}$; Rudson Silva Oliveira2 ${ }^{2}$ Fernando Wallase Carvalho Andrade ${ }^{3}$; \\ Shayanna Mitri Amorim da Rocha Souza ${ }^{4}$
}

\begin{abstract}
RESUMO
O objetivo desse estudo foi avaliar qualitativa e quantitativamente a arborização viária de um trecho da rodovia PA - 275 no município de Parauapebas-PA, caracterizando e fornecendo subsídios para um adequado planejamento arbóreo. Através de um inventário tipo censo, foi realizado diagnóstico no qual foram coletados dados como: nome comum da espécie, família botânica, ocorrência natural (nativa ou exótica) e conflitos das árvores com a rede elétrica. Foram inventariados 884 indivíduos de porte arbóreo, distribuídos em 28 espécies e 14 famílias botânicas. As espécies mais ocorrentes no estudo foram Handroanthus heptaphyllus, Acacia mearnsii e Mangifera indica. Na identificação das espécies, verificou-se que a arborização é composta por $46 \%$ de espécies nativas e $54 \%$ de exóticas. A vegetação do trecho diagnosticado mostrou poucos conflitos com a rede elétrica e elevado número de podas. Quanto ao sistema radicular e a qualidade sanitária das árvores, os resultados foram satisfatórios, visto que grande parte dos indivíduos não causam danos às calçadas e são considerados adequados para arborização urbana. O elevado número de espécies exóticas e a baixa diversidade florística é um aspecto negativo que pode ser melhorado a partir de um programa de enriquecimento utilizando espécies nativas para aumentar a diversidade de espécies.
\end{abstract}

Palavras-chave: Inventário florestal urbano; Planejamento arbóreo; Região amazônica.

\section{ABSTRACT}

The purpose of this study was to evaluate qualitatively and quantitatively the afforestation of a stretch of the PA - 275 highway in the municipality of Parauapebas-PA, characterizing and providing subsidies for proper tree planning. Through a census inventory, a diagnostic was realized and data were collected such as: common name of the species, botanical family, natural occurrence (native or exotic) and conflicts of trees with the power grid. There were inventoried 884 tree-sized individuals, distributed in 28 species and 14 plant families. The most frequent species in the study were Handroanthus heptaphyllus, Acacia mearnsii and Mangifera indica. In the identification of species was found that the afforestation is composed of $46 \%$ of native and $54 \%$ of exotic. The vegetation of diagnosed highway stretch showed few conflicts with the electrical grid and high number of pruning. As for the root system and the sanitary quality of the trees, the results were satisfactory, since most of the individuals do not cause damage to sidewalks and are considered suitable for urban landscaping. The high number of exotic species and low floristic diversity is a negative aspect that can be improved from an enrichment program using native species to increase the diversity of species.

Keywords: Urban forest inventory; Tree planning; Amazon region.

Recebido em 10.11.2015 e aceito em 30.11.2015

1 Graduando do curso de Engenharia Florestal, Universidade Federal Rural da Amazônia. Parauapebas/PA. Email:carielleferro@gmail.com 2 Graduando do curso de Eng. Florestal, Universidade Federal Rural da Amazônia. Parauapebas/PA. Email: rudsonoliveirapbs@gmail.com 3 Professor do curso de Engenharia Florestal, Universidade Federal Rural da Amazônia. Parauapebas/PA. Email: fwcandrade@gmail.com 4 Analista ambiental da Secretaria Municipal de Meio Ambiente, Parauapebas/PA. Email: shayanna.mitri@gmail.com 


\section{INTRODUÇÃO}

A arborização urbana pode ser descrita como a soma de árvores e/ou vegetações que uma cidade apresenta incluindo as que estão presentes nas ruas, avenidas, parques, bosques e demais fragmentos florestais podendo ser de uso público ou privado (MILLER; HAUER; WERNER, 2015). O estudo sobre esse tema vem crescendo nas últimas décadas, abordando o uso de espécies inadequadas, aspectos fitossanitários, percepção ambiental da população, entre outros temas.

Em vias públicas a arborização promove benefícios múltiplos nas cidades, proporcionando conforto aos habitantes através da redução da temperatura, da melhoria da qualidade do solo e do ar, além de amenizar percepções negativas geradas pela urbanização (OLDFIELD et al., 2014). Contudo, a arborização sem planejamento pode trazer problemas e ao invés de um elemento benéfico, passa a representar um foco de conflito com a estrutura urbana.

Na maioria das cidades brasileiras a vegetação arbórea não apresenta planejamento prévio, provocando problemas de manejo (BOBROWSKI; BIONDI, 2014). Para que a vegetação proporcione benefícios, deve haver a idealização do projeto de arborização urbana, priorizando espécies nativas e, consequentemente, diminuindo danos ambientais causados pela introdução de espécies exóticas, como perda de biodiversidade e alterações no ecossistema local (HEJDA; PYSEK; JAROSIK, 2009).

A realização de um inventário florestal pode tornar o planejamento mais eficiente. $O$ inventário consiste em obter informações a respeito da arborização presente no ambiente para conhecer o patrimônio arbustivo e arbóreo de uma localidade, assim como sua distribuição no território. Sua realização proporciona, também, a detecção de possíveis necessidades de poda, tratamentos fitossanitários ou remoção e plantios e a localização de novas áreas para plantio (NOWAK, 2008; NOWAK et al., 2008).

O município de Parauapebas foi criado em 1988 em função do projeto Ferro Carajás da antiga Companhia Vale do Rio Doce, atual Vale S.A, e concentra cerca de $54 \%$ da população total na área urbana (IBGE, 2015). Segundo Bobrowski e Biondi (2014), as prefeituras devem ser agentes promotores do macroplanejamento urbano e ordenar 0 crescimento das cidades, contemplando diretrizes de uso e ocupação do solo, dentro do qual se insere o planejamento da arborização urbana.

O fluxo de pessoas em busca de melhores condições de emprego e bem-estar gera um ciclo de urbanização desenfreado, comprometendo a qualidade de vida da população (OLIVEIRA; AQUINO, 2015). Estas mudanças podem acarretar problemas ambientais, como alterações climáticas, hidrológicas, impermeabilização do solo, poluição (atmosférica, hídrica, 
sonora e visual) e, principalmente, a redução da cobertura vegetal urbana (OLDFIELD et al., 2013).

Tendo em vista que a arborização urbana do município de Parauapebas-PA foi realizada sem planejamento prévio e orientação técnica adequada e o estado atual das espécies plantadas e a diversidade florística no município é desconhecida, o presente trabalho teve como objetivo avaliar qualitativa e quantitativamente a arborização viária de um trecho da rodovia PA - 275, caracterizando e fornecendo subsídios para um adequado planejamento arbóreo.

\section{MATERIAL E MÉTODOS}

O presente trabalho foi realizado em um trecho da rodovia PA-275 no município de Parauapebas, localizado a $06^{\circ} 03^{\prime} 30^{\prime \prime}$ de latitude sul e 49 55' $15^{\prime \prime}$ de longitude oeste.

O município de Parauapebas está inserido na mesorregião do sudeste paraense e dista cerca de $700 \mathrm{Km}$ da capital Belém. Apresenta clima tropical úmido, do tipo "Aw", segundo a classificação de Koppen, e temperatura média anual de $29^{\circ}$ C. A vegetação predominante é Floresta de Terra Firme, a qual sofre alterações tipológicas, de acordo com as variações de solo e relevo, proporcionando a ocorrência dos subtipos: Floresta Densa dos Platôs, Floresta Densa Submontana, Floresta Aberta Latifoliada (cipoal) e Floresta Aberta Mista (cocal) (IDESP, 2015).

A rodovia estadual PA-275 está localizada na região sudeste do estado do Pará e conecta as principais regiões mineradoras da região Norte. Consiste na via de acesso da província mineral de Carajás que abrange as maiores reservas de ferro do mundo (PARADELLA et al., 2015). A rodovia representa o eixo de desenvolvimento de Parauapebas e se trata do principal acesso a este município.

O estudo consistiu de um inventário quali-quantitativo do tipo censo no trecho que apresenta canteiros centrais arborizados, correspondendo a um percurso de sete quilômetros da rodovia (Figura 1), tendo início no viaduto da entrada da cidade e término na portaria da Floresta Nacional de Carajás. 


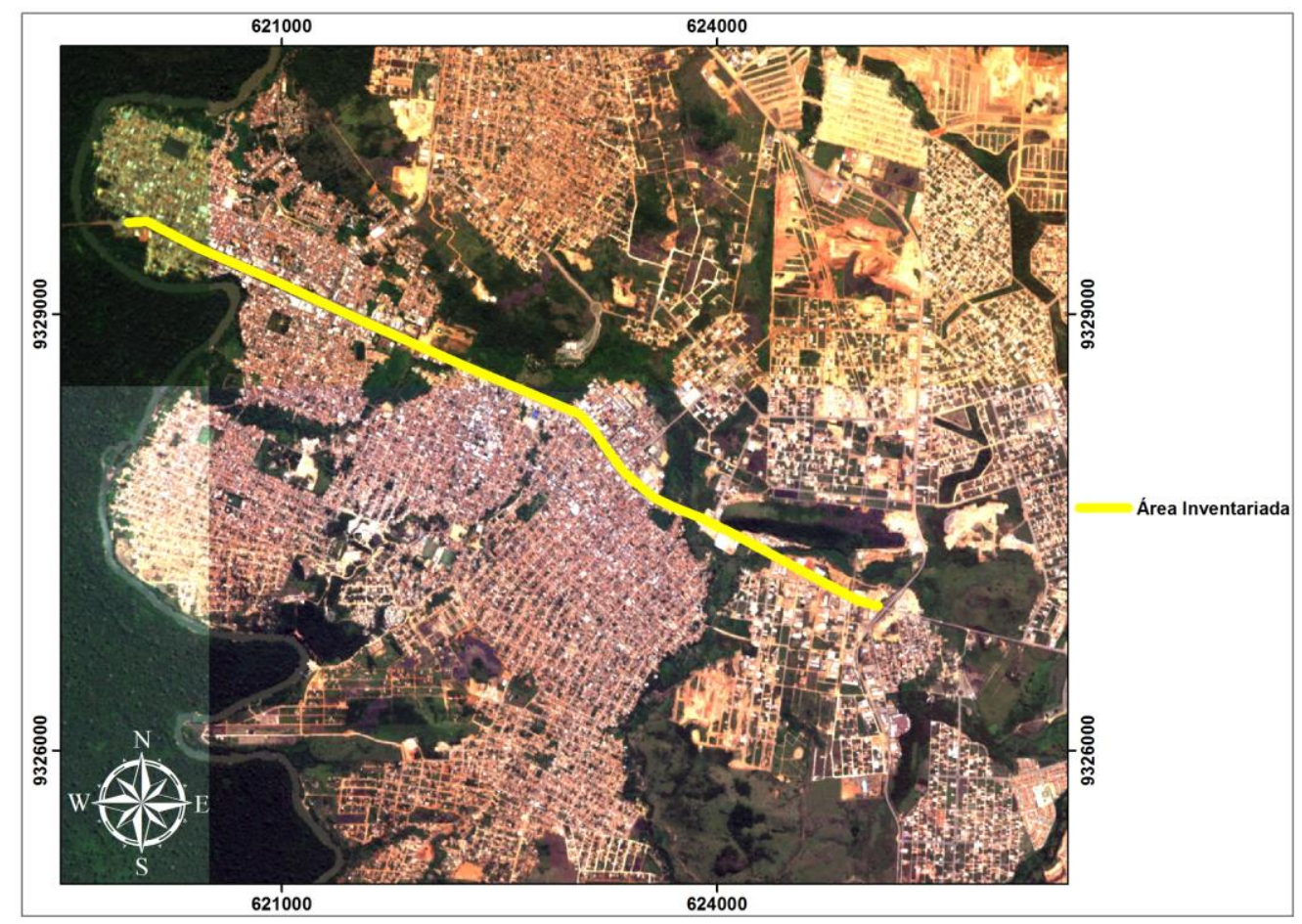

Figura 1. Trecho inventariado da rodovia PA-275 no município de Parauapebas - PA

Figure 1. Inventoried stretch of PA 275 highway in the municipality of Parauapebas - PA

O método empregado consistiu no diagnóstico no qual foram coletados dados tais como: nome comum da espécie, família botânica, ocorrência natural (nativa ou exótica), CAP, posteriormente transformado em DAP (diâmetro a altura do peito, ou seja, a 1,30 m do solo) e conflitos das árvores com a rede elétrica. A coleta dos dados ocorreu no mês Janeiro de 2015.

A classificação das alturas das árvores seguiu o critério de Biondi e Leal (2009), através do qual foram mensuradas espécies de pequeno porte (aquelas que alcançam até $5 \mathrm{~m}$ de altura na fase adulta), médio porte (que alcançam mais que $5 \mathrm{~m}$ e até $10 \mathrm{~m}$ de altura) e de grande porte (aquelas que ultrapassam $10 \mathrm{~m}$ de altura).

Para descrição qualitativa dos indivíduos foram observadas as seguintes características - critérios quanto à fitossanidade: boa (árvore vigorosa e sadia, sem sinais aparentes de ataques de doenças ou injúrias), regular (médias condições de vigor e saúde, necessidade de pequenos reparos), ruim (avançado ou irreversível declínio proveniente de ataques severos de patógenos ou injúria mecânica) e morta (árvores secas ou com morte iminente); - critérios quanto ao desenvolvimento da raiz: sem interferência - quando as raízes não estão expostas; baixa interferência - quando a árvore apresenta alguma raiz exposta na calçada, porém não chega a causar nenhum tipo de prejuízo; média interferência - quando a árvore apresenta várias raízes expostas na calçada, podendo causar algum tipo de prejuízo; alta Interferência - quando a árvore apresenta várias raízes expostas na calçada, já tendo causado algum tipo de prejuízo (FARIA; MONTEIRO; FISCH, 2007). 
Foi avaliado se os indivíduos receberam ou não poda, sendo os podados divididos em: os que receberam poda leve (galhos podados com diâmetro de até $5 \mathrm{~cm}$ ) ou os que receberam poda pesada (aqueles com galhos podados de diâmetro maior que $5 \mathrm{~cm}$ ).

Foi calculada a densidade e frequência absoluta e relativa (\%) de cada espécie. Os dados coletados foram tabulados no software Microsoft Office Excel 2013.

\section{RESULTADOS E DISCUSSÃO}

\section{Composição de espécies da arborização viária}

Foram inventariados 884 indivíduos de porte arbóreo, distribuídos em 28 espécies e 14 famílias botânicas, conforme Tabela 1.

Tabela 1. Relação das espécies encontradas no trecho inventariado da rodovia PA 275, Parauapebas PA

Table 1. List of species found in the inventory section of the PA 275 highway, Parauapebas -PA

\begin{tabular}{|c|c|c|c|c|c|c|c|}
\hline Família & Nome Científico & $\begin{array}{l}\text { Nome } \\
\text { Comum }\end{array}$ & Origem & F.A & $\begin{array}{c}\text { F.R } \\
\%\end{array}$ & D.A & $\begin{array}{c}\text { D.R } \\
\%\end{array}$ \\
\hline Anacardiaceae & Mangifera indica L. & Mangueira & Exótico & 97 & 10,97 & 138,57 & 10,97 \\
\hline Anacardiaceae & Anacardium occidentale $\mathrm{L}$. & Cajú & $\begin{array}{l}\text { Nativa } \\
\text { do Brasil }\end{array}$ & 10 & 1,13 & 14,29 & 1,13 \\
\hline Anacardiaceae & Spondias mombin L. & Cajá & Exótico & 3 & 0,34 & 4,29 & 0,34 \\
\hline Apocynaceae & Thevetia peruviana K. Schum. & $\begin{array}{l}\text { Chapéu-de- } \\
\text { napoleão }\end{array}$ & Exótico & 1 & 0,11 & 1,43 & 0,11 \\
\hline Bignoniaceae & Tabebuia roseoalba (Ridl.) & Ipê-branco & $\begin{array}{l}\text { Nativa } \\
\text { do Brasil }\end{array}$ & 14 & 1,58 & 20,00 & 1,58 \\
\hline Bignoniaceae & $\begin{array}{l}\text { Handroanthus heptaphyllus } \\
\text { (Vell.) Mattos }\end{array}$ & Ipê-rosa & $\begin{array}{l}\text { Nativa } \\
\text { do Brasil }\end{array}$ & 342 & 38,69 & 488,57 & 38,69 \\
\hline Chrysobalanaceae & $\begin{array}{c}\text { Licania tomentosa (Benth.) } \\
\text { Fritsch }\end{array}$ & Oiti & $\begin{array}{l}\text { Nativa } \\
\text { do Brasil }\end{array}$ & 1 & 0,11 & 1,43 & 0,11 \\
\hline Combretaceae & Terminalia catappa L. & Sete-copas & Exótico & 6 & 0,68 & 8,57 & 0,68 \\
\hline Fabaceae & Acacia mangium Willd. & $\begin{array}{l}\text { Acacia- } \\
\text { mangium }\end{array}$ & Exótico & 32 & 3,62 & 45,71 & 3,62 \\
\hline Fabaceae & Acacia mearnsii De Wild. & $\begin{array}{l}\text { Acacia- } \\
\text { negra }\end{array}$ & Exótico & 189 & 21,38 & 270,00 & 21,38 \\
\hline Fabaceae & Adenanthera pavonina L. & $\begin{array}{l}\text { Tento- } \\
\text { carolina }\end{array}$ & Exótico & 36 & 4,07 & 51,43 & 4,07 \\
\hline Fabaceae & Cenostigma tocantinum Ducke & Pau-preto & $\begin{array}{l}\text { Nativa } \\
\text { do Brasil }\end{array}$ & 23 & 2,60 & 32,86 & 2,60 \\
\hline Fabaceae & $\begin{array}{c}\text { Delonix regia (Bojer ex Hook.) } \\
\text { Raf. }\end{array}$ & Flamboyant & Exótico & 11 & 1,24 & 15,71 & 1,24 \\
\hline Fabaceae & $\begin{array}{c}\text { Leucaena leucocephala (Lam.) } \\
\text { de Wit }\end{array}$ & Leucaena & Exótico & 4 & 0,45 & 5,71 & 0,45 \\
\hline Fabaceae & $\begin{array}{c}\text { Inga cinnamomea Spruce ex } \\
\text { Benth. }\end{array}$ & Ingá-chinelo & $\begin{array}{l}\text { Nativa } \\
\text { do Brasil }\end{array}$ & 2 & 0,23 & 2,86 & 0,23 \\
\hline Fabaceae & $\begin{array}{l}\text { Cassia ferruginea (Schrad.) } \\
\text { Schrader ex DC. }\end{array}$ & $\begin{array}{l}\text { Chuva-de- } \\
\text { ouro }\end{array}$ & $\begin{array}{l}\text { Nativa } \\
\text { do Brasil }\end{array}$ & 1 & 0,11 & 1,43 & 0,11 \\
\hline Malpighiaceae & Byrsonima crassifolia (L.) Kunth & Murici & $\begin{array}{l}\text { Nativa } \\
\text { do Brasil }\end{array}$ & 1 & 0,11 & 1,43 & 0,11 \\
\hline Malvaceae & $\begin{array}{l}\text { Theobroma grandiflorum (Willd. } \\
\text { ex Spreng.) K. Schum. }\end{array}$ & Cupuaçu & $\begin{array}{l}\text { Nativa } \\
\text { do Brasil }\end{array}$ & 3 & 0,34 & 4,29 & 0,34 \\
\hline Meliaceae & Swietenia macrophylla King. & Mogno & $\begin{array}{l}\text { Nativa } \\
\text { do Brasil }\end{array}$ & 2 & 0,23 & 2,86 & 0,23 \\
\hline Moraceae & Fícus benjamina $\mathrm{L}$. & Ficus & Exótico & 6 & 0,68 & 8,57 & 0,68 \\
\hline Moraceae & Artocarpus heterophyllus Lam. & Jaca & Exótico & 3 & 0,34 & 4,29 & 0,34 \\
\hline Myrtaceae & Syzygium jambos (L.) Alston & Jambo & Exótico & 75 & 8,48 & 107,14 & 8,48 \\
\hline
\end{tabular}




\begin{tabular}{|c|c|c|c|c|c|c|c|}
\hline Família & Nome Científico & $\begin{array}{l}\text { Nome } \\
\text { Comum }\end{array}$ & Origem & F.A & $\begin{array}{c}\text { F.R } \\
\%\end{array}$ & D.A & $\begin{array}{c}\text { D.R } \\
\%\end{array}$ \\
\hline Myrtaceae & Psidium guajava L. & Goiaba & $\begin{array}{l}\text { Nativa } \\
\text { do Brasil }\end{array}$ & 10 & 1,13 & 14,29 & 1,13 \\
\hline Myrtaceae & $\begin{array}{l}\text { Syzygium cacuminis (Craib) } \\
\text { Chantar. \& J. Parn. }\end{array}$ & Jambolão & Exótico & 5 & 0,57 & 7,14 & 0,57 \\
\hline Myrtaceae & $\begin{array}{c}\text { Eucalyptus ser. Accedentes Chip } \\
\text { pend. }\end{array}$ & Eucalipto & Exótico & 1 & 0,11 & 1,43 & 0,11 \\
\hline Oxalidaceae & Averrhoa carambola L. & Carambola & Exótico & 1 & 0,11 & 1,43 & 0,11 \\
\hline Rubiaceae & Genipa americana L. & Jenipapo & $\begin{array}{l}\text { Nativa } \\
\text { do Brasil }\end{array}$ & 2 & 0,23 & 2,86 & 0,23 \\
\hline \multirow[t]{2}{*}{ Sapotaceae } & Pouteria oblanceolata Pires & Tuturuba & $\begin{array}{l}\text { Nativa } \\
\text { do Brasil }\end{array}$ & 3 & 0,34 & 4,29 & 0,34 \\
\hline & & & TOTAL & 884,0 & 100,0 & 1262,86 & 100,0 \\
\hline
\end{tabular}

Nota: F.A = Frequência absoluta, F.R\% = Frequência Relativa, D.A = Densidade absoluta, D.R\% = Densidade relativa

As espécies mais ocorrentes no estudo foram Handroanthus heptaphyllus, Acacia mearnsii e Mangifera indica, que juntas correspondem a $71 \%(\mathrm{~N}=629)$ do total amostrado. A família Bignoniaceae apresentou a maior porcentagem de indivíduos, cerca de $40 \%$, seguida da Fabaceae (33,71\%), Anacardiaceae (12,44\%) e Myrtaceae (10,29\%), enquanto que as demais apresentaram percentagem menor do que 1\% (Figura 2).

A espécie Handroanthus heptaphyllus (ipê-rosa) apresentou maior frequência de indivíduos (39\%). Este fato é preocupante porque se a referida espécie for atingida por alguma praga ou doença, a arborização de toda a região inventariada será comprometida. Haas et al. (2011) ressaltam que a utilização de um maior número de espécies na arborização urbana viabiliza a distribuição dos riscos, uma vez que, evidências empíricas sugerem que a baixa diversidade pode aumentar a invasão por patógenos e a transmissão de doenças.

O predomínio de Handroanthus heptaphyllus na arborização urbana também foi observado por Silva, Leite e Tonello (2014) em Araçoiaba da Serra - SP. A grande frequência (39\%) dessa espécie está condicionada à beleza de sua floração, tornando-a uma das espécies mais populares em paisagismo e arborização de ruas e avenidas desprovidas de rede elétrica.

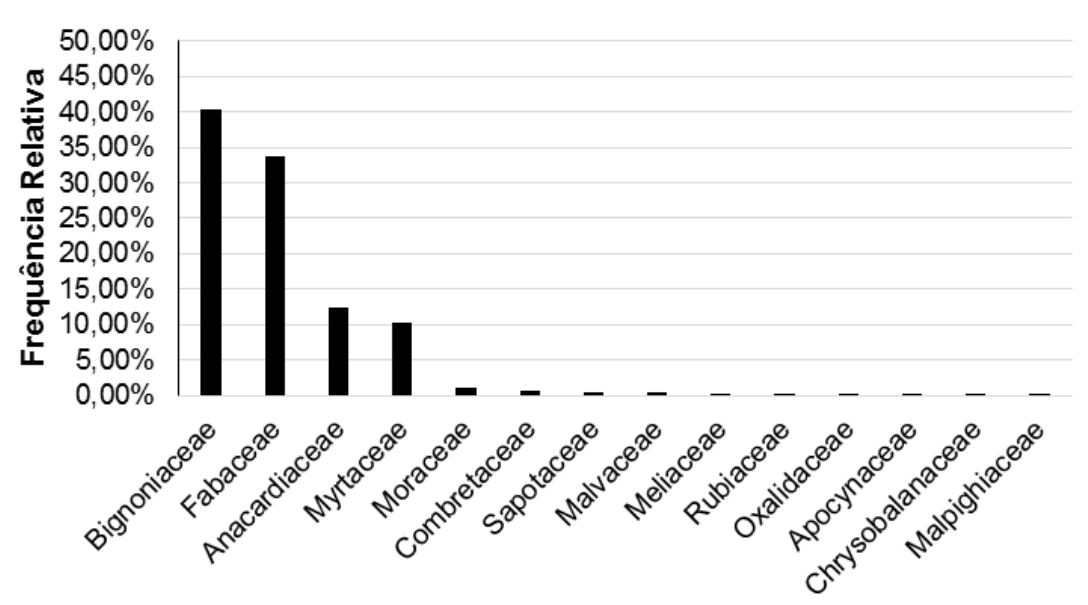

Figura 2. Frequência relativa das famílias botânicas

Figure 2. Relative frequency of botanical families 
$\mathrm{Na}$ análise das espécies, verificou-se que a arborização do trecho inventariado é composta por $46 \%$ de espécies nativas e $54 \%$ de exóticas. Resultados similares foram encontrados por Silva et al. (2007) em Pato Branco - PR, onde os autores obtiveram 121 espécies, sendo $44 \%$ nativas e 55\% exóticas. Dentre as espécies exóticas, a que apresentou maior frequência foi a Acacia mearnsii De Wild. com 189 exemplares.

Segundo Lorenzi (2008), o plantio de espécies de árvores nativas em ruas, avenidas, parques e praças públicas nas cidades brasileiras é uma prática pouco empregada, a despeito da riqueza da flora nativa. Isso ocorre, sobretudo, por desconhecimento desta. Desde o início da colonização, espécies foram trazidas de outros países para arborizar ruas e praças no Brasil. Estima-se que mais de $80 \%$ das árvores cultivadas nas ruas das cidades brasileiras são da flora exótica.

As espécies exóticas podem apresentar vantagens competitivas sobre as nativas, acarretando sua dominância em áreas naturais e, consequentemente, a perda de indivíduos ou até de espécies nativas nos remanescentes naturais (RICHARDSON; PYSEK, 2006).

Foram encontradas 11 espécies frutíferas, representando 24\% da composição arbórea da área estudada. A espécie que possui maior número de indivíduos é a Mangifera indica L., num total de 97, demonstrando ações não planejadas, feitas de forma espontânea pela população com a finalidade de alimentação humana.

A avaliação do estado geral das árvores inventariadas (Figura 3) mostrou que a maioria (90,38\%) apresentou um bom estado, ou seja, não demonstravam sintomas de doenças ou injúrias, 4,75\% delas apresentavam estado regular, acompanhado de 4,19\% em estado ruim e apenas $0,68 \%$ estavam mortas. Pires et al. (2010), ao diagnosticarem a arborização urbana de Goiandira/GO constataram que $84 \%$ dos indivíduos estavam em bom estado e apenas $13 \%$ estavam em estado ruim ou regular.

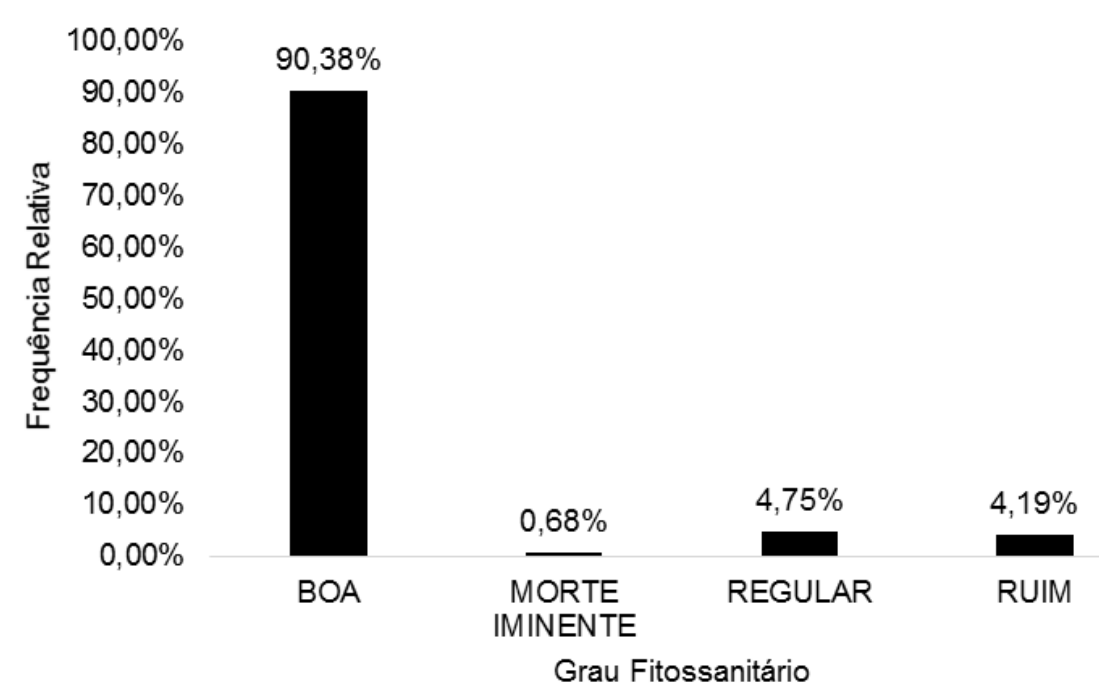

Figura 3. Avaliação do estado fitossanitário das árvores

Figure 3. Rating of plant health of the trees 
Dentre os indivíduos que apresentaram estado fitossanitário ruim foi verificada a presença de uma planta parasita, popularmente conhecida como erva-de-passarinho. Estas plantas não ocasionam danos diretos ao hospedeiro (retirada dos elementos minerais). Entretanto, dependendo da intensidade de recobrimento, podem interferir no processo de respiração através da casca, afetando sua vitalidade e, também, facilitar a ocorrência de danos causados por insetos que habitam este ambiente (perfuração da casca e contaminação por agentes patogênicos) (MOURÃO et al., 2009).

Em relação aos conflitos existentes entre as árvores e as redes elétricas no trecho inventariado apenas $8,48 \%$ apresentaram algum tipo de interferência. Esse resultado é similar ao encontrado por Santos et al. (2013) em Lages - SC, onde 8,05\% dos indivíduos interferiam na rede elétrica. A baixa interferência deve-se à manutenção que as árvores recebem, com podas constantes. Para reduzir a ocorrência desses danos, devem ser selecionadas árvores de porte compatível com redes elétricas e interferências subterrâneas. Aquelas que se caracterizam por apresentarem a madeira mole, caule e ramos quebradiços devem ser evitados, pois são vulneráveis a chuvas e ventos fortes, colocando em risco a segurança de pedestres, veículos e edificações (MOTTER; MULLER, 2012).

A análise da condição do sistema radicular mostrou que $90,72 \%$ dos indivíduos não apresentaram danos as calçadas (Figura 4). Resultados similares foram obtidos por Silva, Leite e Tonello (2014) em Araçoiaba da Serra - SP, onde a maior parte dos indivíduos (80,56\%) não apresentaram raízes aparentes no solo. Dos 9,28\% que apresentam interferência, apenas 0,57\% causam alta interferência. Este resultado é baixo quando comparado ao de Motter e Muller (2012), no qual 8\% obtiveram alta interferência já tendo causado prejuízos às calçadas.

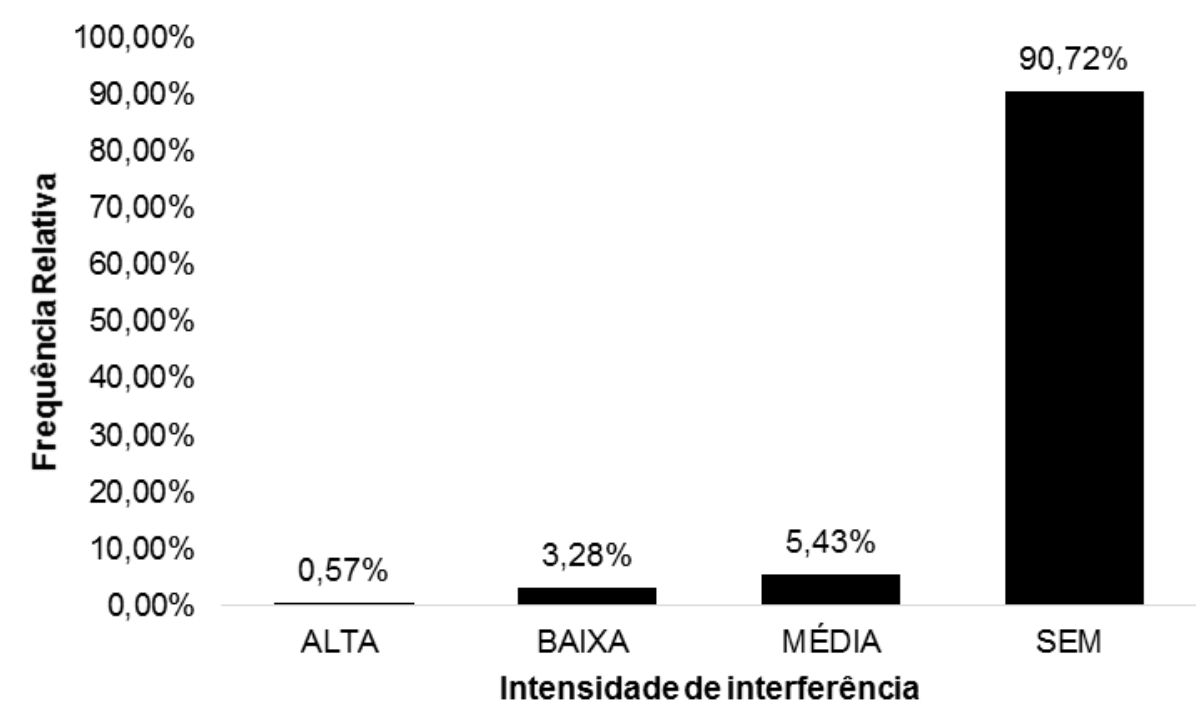

Figura 4. Interferência do sistema radicular nas calçadas

Figure 4. Interference of the root system on sidewalks 
No presente estudo $85,97 \%$ dos indivíduos sofreram poda lateral, $0,90 \%$ poda pesada e 13,12\% não sofreram nenhum tipo de poda (Figura 5). Esses resultados são similares aos encontrados por Souza et al. (2014) em São Joaquim - SC, onde a poda foi observada na maioria das árvores (65\%), destas $14 \%$ receberam poda pesada e $86 \%$ poda leve. 0 motivo das podas, muitas vezes, deve-se à interferência de galhos nas redes elétricas. No entanto, as podas excessivas conferem um aspecto negativo às árvores, pois atrapalham o seu desenvolvimento natural, além de deixarem os indivíduos susceptíveis à entrada de fitopatógenos. Recomenda-se que árvores de maior porte sejam substituídas pelas de menor porte que, além de reduzir os custos dos órgãos públicos com podas, serão esteticamente agradáveis exibindo sua arquitetura natural.

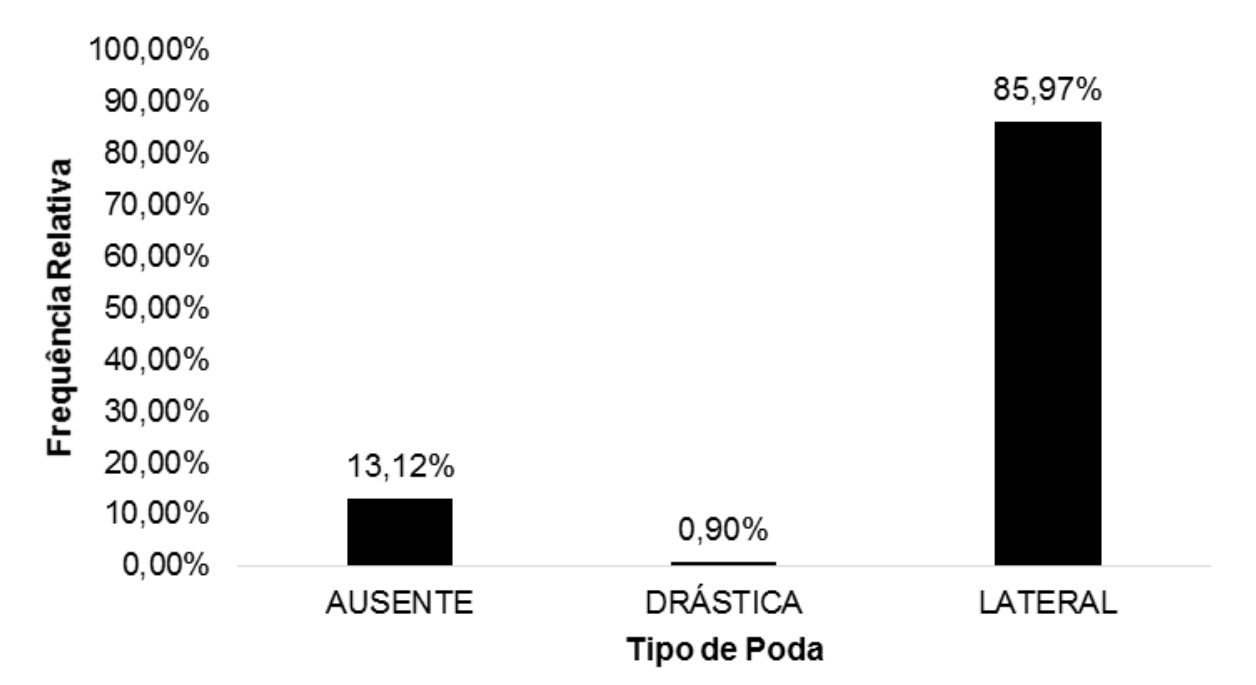

Figura 5. Análise quanto ao tipo de poda

Figure 5. Analysis of the type of pruning

Com relação ao DAP das árvores, o menor valor observado foi 6,52 cm e o maior 155 $\mathrm{cm}$, com média de $31,18 \mathrm{~cm}$. Na análise da altura total das árvores, observou-se que mais de $15 \%$ dos indivíduos apresentam altura menor do que $5 \mathrm{~m}, 61 \%$ entre 5 e $10 \mathrm{~m}$, e 24\% apresentam altura superior a $10 \mathrm{~m}$. A altura média das árvores foi de $8,70 \mathrm{~m}$. Estes resultados indicam que a maioria das espécies inventariadas são de porte médio a grande.

As duas espécies com maior número de indivíduos possuem altura entre 10 e $20 \mathrm{~m}$ (Handroanthus heptaphyllus) e entre 5 e $15 \mathrm{~m}$ (Acacia mearnsii). Essas espécies são recomendadas para arborização de ruas e avenidas desprovidas de rede elétrica (LORENZI, 2008). No trecho inventariado há predominância dessas fiações, isso explica porque $86 \%$ dos indivíduos sofreram algum tipo de poda. Para arborização de ruas onde há rede elétrica devese priorizar espécies de pequeno porte (SANTOS et al., 2013). 
A altura da primeira ramificação indica se há interferência das árvores no trânsito de pedestres e/ou veículos. Para que não haja interferência, é recomendável que essa altura não seja inferior a $2,0 \mathrm{~m}$. Cerca de $45 \%$ dos indivíduos obtiveram ramificações dentro do recomendado. Esse percentual é superior ao encontrado por Melo, Filho e Júnior (2007), na cidade de Patos-PB, onde pouco mais de $20 \%$ das árvores apresentavam a altura considerada ideal para facilitar a passagem de pedestres. A altura da primeira ramificação baixa, associada às calçadas mais estreitas, faz com que as árvores interfiram no trânsito dos pedestres, tornando-se um aspecto negativo nas cidades.

\section{CONCLUSÕES}

Foram inventariados 884 indivíduos de porte arbóreo, distribuídos em 28 espécies e 14 famílias botânicas. As espécies mais ocorrentes no estudo foram Handroanthus heptaphyllus, Acacia mearnsii e Mangifera indica.

A maioria dos indivíduos do trecho inventariado apresenta porte médio a grande.

O sistema radicular e a qualidade sanitária das árvores foram satisfatórios, visto que grande parte dos indivíduos não causam danos às calçadas e não demonstram sintomas de doenças ou injúrias, sendo considerados adequados para arborização urbana.

O elevado número de espécies exóticas é um aspecto negativo que pode ser melhorado a partir de um programa de enriquecimento utilizando espécies nativas para aumentar diversidade de espécies.

\section{AGRADECIMENTOS}

Ao departamento de Projetos e Convênios da Secretaria Municipal de Meio Ambiente da cidade de Parauapebas e a Universidade Federal Rural da Amazônia pelo apoio técnico para a execução deste trabalho.

\section{REFERÊNCIAS}

BIONDI, D. LEAL, L. Avaliação de espécies plantadas experimentalmente na arborização de ruas da cidade de Curitiba - PR. Revista da Sociedade Brasileira de Arborização Urbana, Piracicaba, v. 4, n. 4, p. 79-99, 2009.

BOBROWSKI, R.; BIONDI, D. Gestão da arborização de ruas - estudo de caso na cidade de Curitiba, Paraná, Brasil. Revista da Sociedade Brasileira de Arborização Urbana, Piracicaba, v. 9, n. 4, p 132-150, 2014. 
FARIA, J. L.G.; MONTEIRO, E. A.; FISCH, S. T. V. Arborização de vias públicas do município de Jacareí - SP, Brasil. Revista da Sociedade Brasileira de Arborização Urbana, Piracicaba. v.2, n.4, p. 20-33, 2007.

HAAS, S. E.; HOOTEN, M. B.; RIZZO, D. M.; MEENTEMEYER, R. K. Forest species diversity reduces disease risk in a generalist plant pathogen invasion. Ecology Letters, Oxford, v. 14, n. 11, p. 1108-1116, 2011.

HEJDA, M.; PYŠEK, P.; JAROŠÍK, V. Impact of invasive plants on the species richness, diversity and composition of invaded communities. Journal of Ecology, England, v. 97, p. 393403, 2009.

INSTITUTO BRASILEIRO DE GEOGRAFIA E ESTATÍSTICA (IBGE). Parauapebas em Dados. Disponível em: <http://www.ibge.gov.br/cidadesat/topwindow.htm?1> Acesso em: 09 jul. 2015.

INSTITUTO DE DESENVOLVIMENTO ECONÔMICO, SOCIAL E AMBIENTAL DO PARÁ (IDESP). Estatística municipal de Parauapebas. Disponível em: <www.idesp.pa.gov.br/pdf/EstatisticaMunicipal/pdf/Parauapebas.pdf> Acesso em 20 jul. 2015.

LORENZI, H. Árvores brasileiras: manual de identificação e cultivo de plantas arbóreas do Brasil. 5 ed. Nova Odessa, SP: Instituto Plantarum, v. 1. 2008.

MELO, R. M.; FILHO, J. A. L.; JÚNIOR, F. R. Diagnóstico qualitativo e quantitativo da arborização urbana no bairro Bivar Olinto, patos, paraíba. Revista da Sociedade Brasileira de Arborização Urbana, Piracicaba, v. 2, n. 1, p. 64-80, 2007.

MILLER, R. W.; HAUER, R. J.; WERNER, L. P. Urban forestry: planning and managing urban greenspaces. Waveland Press, 2015.

MOTTER, N.; MULLER N. G. DIAGNÓSTICO DA ARBORIZAÇÃO URBANA NO MUNICÍPIO DE TUPARENDI-RS. Revista da Sociedade Brasileira de Arborização Urbana, Piracicaba, v.7, n.4, p.27-36, 2012.

MOURAO, F. A.; JACOBI, C. M.; FIGUEIRA, J. E. C.; BATISTA, E. K. L. Effects of the parasitism of Struthanthus flexicaulis (Mart.) Mart. (Loranthaceae) on the fitness of Mimosa calodendron Mart. (Fabaceae), an endemic shrub from rupestrian fields over ironstone outcrops, Minas Gerais State, Brazil. Acta Botanica Brasilica, Belo Horizonte, v.23, n.3, p 820825, 2009.

NOWAK, D. J. Assessing Urban Forest Structure: Summary and Conclusions. Arboriculture \& Urban Forestry, Champaign, v. 34, n.6, p. 391-392, 2008.

NOWAK, D. J.; CRANE, D. E.; STEVENS, J. C.; HOEHN, R. E.; WALTON, J. T.; BOND, B. A ground-based method of assessing urban forest structure and ecosystem services. Arboriculture \& Urban Forestry, Champaign, v. 34, n. 6, p. 347-358, 2008.

OLDFIELD, E. E.; FELSON, A. J.; WOOD, S. A.; HALLETT, R. S.; STRICKLAND, M. S.; BRADFORD, M. A. Positive effects of afforestation efforts on the health of urban soils. Forest Ecology and Management, Amsterdam, v. 313, p. 266-273, 2014.

OLDFIELD, E. E.; WARREN, R. J.; FELSON, A. J.; BRADFORD, M. A. Challenges and future directions in urban afforestation. Journal of Applied Ecology, England, v. 50, n.5, p.11691177, 2013. 
OLIVEIRA, C.E; AQUINO, C.M.S. Crescimento urbano e impactos sobre a cobertura vegetal no bairro vale do gavião - Teresina - PI-BR. Revista da Casa da Geografia de Sobral, Sobral/CE, v. 17, n. 2, p. 68-84, 2015.

PARADELLA, W. R.; FERRETTI, A.; MURA, J. C.; COLOMBO, D.; GAMA, F. F.;TAMBURINI, A.; SANTOS, A. R.; NOVALI, F.; GALO, M.; CAMARGO, P. O.; SILVA, A. Q.; SILVA, G.G.; SILVA, A.; GOMES, L. L. Mapping surface deformation in open pit iron mines of Carajás Province (Amazon Region) using an integrated SAR analysis. Engineering Geology. v. 193, p. 61-78, 2015.

PIRES, N. A. M. T.; MELO, M. S.; OLIVERA, D, E de; SANTOS, S. X. A arborização urbana do município de Goiandira/GO - caracterização quali-quantitativa e proposta de manejo. Revista da Sociedade Brasileira de Arborização Urbana, Piracicaba, v. 5, n. 03, p. 185-205, 2010.

RICHARDSON, D. M.; PYSEK, P. Plant invasions: merging the concepts of species invasiveness and community invisibility. Progress in Physical Geography, Los Angeles, v. 30, n. 3. P. 409-431, 2006.

SANTOS, E. M. dos; SILVEIRA, B. D. B. da; SOUZA, A. C.; SCHMITZ, V.; SILVA, A. C. da; HIGUCHI, P. Análise quali-quantitativa da arborização urbana em Lages, SC. Revista de Ciências Agroveterinárias, Lages, v.12 n.1, p. 59-67, 2013.

SILVA, L. M.; MOCCELLIN, R.; WEISSHEIMER, D. I.; ZBORALSKI, A. R.; FONSECA, L.; RODIGHIERO, D. A. Inventário e sugestões para arborização em via pública de Pato Branco, Paraná, Brasil. Revista da Sociedade Brasileira de Arborização Urbana, Piracicaba, v. 2, n. 1, p. 101-118, 2007.

SILVA, T. G.; LEITE, E. C.; TONELLO, K. C. Inventário da arborização urbana no município de Araçoiaba da Serra, São Paulo, Brasil. Revista da Sociedade Brasileira de Arborização Urbana, Piracicaba, v.9, n.4, p 151-169, 2014.

SOUZA, P. F. de; BOURSCHEID, C. B.; POMPÉO, P. N.; STANG, M. B.; MANFROI, J.; RODRIGUES, M. D. S.; SILVA, A. C. da; HIGUCHI, P. Inventário e recomendações para a arborização do centro da cidade de São Joaquim, Santa Catarina, Brasil. Revista da Sociedade Brasileira de Arborização Urbana, Piracicaba, v.9, n.4, p 99-112, 2014. 